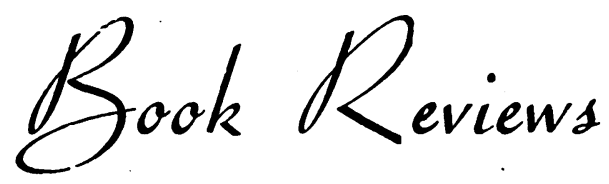

\section{THE CARE OF THE EXPECTANT MOTHER}

By Josephine Barnes, D.M., F.R.C.S., F.R.C.O.G. Pp. $x+270$, illustrated. London: Pitman Medical Publishing Co. Ltd. I956. 30s.

It is particularly timely that this book should appear when intensive research is being carried out into ways of promoting better collaboration between the three branches of medicine concerned with the care of the expectant mother and with the delivery of her baby. These three branches are the specialist, the general practitioner and the midwife.

The book is written by a specialist, who is herself a most gifted teacher with a rare ability to attract students in large numbers to her lectures and ward rounds.

The book is designed for the general practitioner and senior midwife: but mainly for the general practitioner.

The book is written clearly and without any waste of words. It is different from the ordinary text book of midwifery in many respects; being copiously illustrated with exceedingly well-produced drawings, diagrams and $\mathrm{x}$-rays.

There is adequate attention to the diagnosis of the normal and the abnormal in pregnancy.

There is certainly sufficient information about development and about normal anatomy for all qualifying examinations and also enough for the D.R.C.O.G.

The value of good ante-natal care is stressed in chapter after chapter, although it is a little strange to find Miss Barnes saying that it is unnecessary to examine the abdomen until the 32 nd week, unless abdominal symptoms develop or the uterus becomes excessively large.

The chapter dealing with the Rhesus factor is especially lucid. Such details as how to test urine are clearly and fully given. Enough is given to help in the diagnosis of malpresentation.

Sensible and adequate advice is given about antepartum haemorrhage.

Diets, as one would expect from a disciple of Professor F. J. Browne, and the whole management of toxaemia, is beautifully done, as are chapters on the diseases that may co-exist with pregnancy.

All in all, this book is one that every general practitioner who is practising midwifery at home, should possess, for the style makes it easy to read, the message of good ante-natal care and midwifery is clearly put across and unnecessary wordiness has been completely spared.

E.E.P.

\section{MUNRO KERR'S OPERATIVE OBSTETRICS}

By J. Chassar Moir, Hon.LL.D., M.A., M.D., F.R.C.S., F.R.C.O.G. Sixth edition. Pp. $x+$ I008, with 407 illustrations. London: Bailliere, Tindall and Cox, Ltd. 1957. £5 5s.

This book, in the lifetime of both authorsMunro Kerr who wrote the first editions and Chassar Moir who has virtually re-written this edition-has rightly become a classic.

It is a book for specialists. In fact, every specialist who practises operative obstetrics should possess a copy. In its thousand pages it contains a very full extract of world literature on almost every subject it tackles. For instance, on one page dealing with appendicitis in pregnancy which itself contains only about 300 words, there are references to 12 other publications. It also contains Professor Chassar Moir's views as to the treatment he himself uses in most instances.

There is an exceptionally fine chapter on Caesarean Section, and the steps in the operation are now beautifully illustrated by colour photographs taken from a film of the operation.

Such procedures as symphysiotomy, which may be thought to be an outdated operation by some, is treated seriously over nine pages with all the pros and cons of the operation properly examined.

Everywhere throughout the text the interest of the reader is kept up by well written quotations from case histories; some of these from Munio Kerr's own unbelievably extensive practice, others from Professor Chassar Moir's, and others from the literature.

A subject such as ectopic pregnancy is dealt with from the standpoint of pathological anatomy, clinical typing and, of course, from the operative procedure aspect.

There is so much in this book that it is sometimes a little difficult to find one's way around, in particular, when searching for such a relatively newly popular procedure as the Brandt-Andrews manoeuvre. The reviewer was unable to find any mention of it in the index, nor was it possible to find the manoeuvre in the initial chapter which concerns the prevention of post partum haemorrhage, nor where he writes about the use of intravenous ergometrine. It was found eventually in the chapter dealing with post partum haemorrhage and it was given a very fair review. For a student working for a higher examination, the inability to learn all about one particular subject in one chapter 
may make for difficulty and perhaps the work could be improved by better integration of the chapters.

This is not an adverse criticism of the book. It is merely a constructive criticism for the future, for there is no doubt that this work is the most useful book on operative obstetrics today in the English language. It is also the most beautifully produced and one of the most worth-while books on obstetrics in the whole of modern medical literature.

E.E.P.

\section{THE MANAGEMENT OF ABDOMINAL OPERATIONS}

\section{in two volumes}

Edited by Rodney Maingot, F.R.C.S. Second edition. Pp. xvi +1432 , with 640 illustrations. London: H. K. Lewis \& Co. Ltd. 1957. $£ 8$.

This is the second edition of an important surgical textbook. The first edition has been completely re-edited: and although the authors of most of the chapters are unchanged, they have brought their work as up to date as it is possible to do in the production of so large a book. The previous single cumbersome volume is replaced by two somewhat lighter ones, and the number of pages is increased by 126 . The index, which has been made even more complete, is to be found in both volumes. The whole is well put together, illustrations are simple and clear, and $\mathrm{x}$-ray pictures are carefully chosen and skilfully reproduced, with the single exception of fig. 175 which is printed upside down and shows a Bilroth I. gastrectomy emptying vertically upwards.

The object of the book is the complete presentation of all the practical aspects of abdominal surgery: and this object is more than fulfilled by the 32 contributors who have produced the 45 chapters. Naturally there is some repetition; but it is clear that the editor has taken great pains to make the book into a comprehensive whole, so that it is possible to read it through with a sustained interest and a clear sense of continuity. The book presupposes a reasonable knowledge of medicine and surgery, and one is spared the elementary considerations which introduce each chapter in so many other textbooks. The minute details of operative surgery are àlso omitted, whereas the type of operation to be done and the conditions which determine the choice are fully discussed. Thus the bookwhich will appeal most of all to postgraduates and fellowship candidates-is easily read and appreciated by the experienced surgeon, and forms a storehouse of information which would be otherwise available to him only in a large assortment of articles in a variety of journals.

Upwards of one-third of the book involves physiological considerations, and the chapters on fluid and electrolyte balance by L. P. le Quesne is especially recommended as being an outstanding example of the conciseness and clarity which characterises the whole work. A number of the chapters such as 'Preparation of the Good Risk
Patient,' 'The Role of Vitamins in Abdominal Surgery,' and ' Post-operative Parotitis,' while perhaps necessary for completeness, are unavoidably a little humdrum; and to my mind the most excellent chapter on anaesthesia by J. A. Lee will be of less interest to the general surgeon than the rest of the book. Nevertheless, in a work of this size there are bound to be some bleak spots, and these are more than compensated by the sustained interest of the remainder. General considerations occupy about one-third of the book, the remaining twothirds being devoted to regional problems. These chapters are well written, clearly illustrated and completely authoritative. Outstanding among them are those on gastric and duodenal ulcer and their complications by Mr. Maingot himself, and on the cardia and oesophagus by John Borrie. Over 300 pages are devoted to the stomach and duodenum and not a word is wasted. The little essay on infantile pyloric stenosis by David Levi is a model of clarity and common sense. Among the other chapters, the discussion of surgical aspects of pancreatic disease by E. G. Muir, and of the colon and rectum by $H$. R. Thompson are excellent, and the latter is especially well illustrated by diagrams and photographs.

Considered as a whole, the book is a very comprehensive survey of almost all possible problems associated with abdominal surgery. It is eminently readable, beautifully produced and, although expensive, is certainly worth the money.

\section{J.L.S.}

\section{THE DOCTOR, HIS PATIENT, AND THE ILLNESS}

By Michael Balint, M.D. Pp. $x+355$. London: Pitman Publishing Co. Ltd. 1957. 40s.

This is an exciting book about the oldest drug in the world. Considered by many to be, at best, a form of placebo, Dr. Balint successfully demonstrates it to be the most potent in our therapeutic armamentarium. And the drug? The doctor himself. This is an account of a long-term research project aimed at elucidating for practical purposes the very complex relationship which exists between the doctor and his patient. A team of 14 general practitioners and a psychiatrist met in a weekly seminar for several years to discuss their patients, their problems and themselves. The discussions were recorded verbatim and from this rich collection of data the author has edited in a very able manner the dominant theme which is basic to his main contention-that what the doctor does, and how he does it, is more important to the patient than all the E.C.ros and consultations.

It is now accepted that almost half of the patients who attend surgery possess psychological problems which have a direct bearing upon their complainteven at times upon the complaints of their spouse or their children! Unless these basic problems are tackled there can be little hope of effecting a complete and lasting cure at somatic level. In this book we read how these 14 doctors courageously pre- 